\title{
Effect of pulmonary vascular resistance before left ventricular assist device implantation on short- and long-term post-transplant survival
}

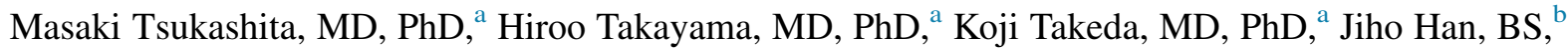 \\ Paolo C. Colombo, MD, ${ }^{\mathrm{c}}$ Melana Yuzefpolskaya, MD, ${ }^{\mathrm{c}}$ Veli K. Topkara, MD, ${ }^{\mathrm{c}}$ Arthur Reshad Garan, MD, \\ Donna M. Mancini, MD, ${ }^{c}$ Paul A. Kurlansky, MD, ${ }^{d}$ and Yoshifumi Naka, MD, $\mathrm{PhD}^{\mathrm{a}}$
}

\begin{abstract}
Objectives: Pulmonary hypertension is often considered a contraindication to orthotopic heart transplantation. Left ventricular assist device support may improve pulmonary hypertension by unloading the left ventricle, making patients eligible for transplantation. We sought to investigate the effect of continuous-flow left ventricular assist device support on pulmonary hypertension and compare posttransplantation outcomes in patients with preexisting pulmonary hypertension.
\end{abstract}

Methods: Between March 2004 and December 2013, 256 potential orthotopic heart transplantation candidates underwent continuous-flow left ventricular assist device implantation at Columbia University. Preimplantation right heart catheterization data were available for 227 patients. Patients were divided into 2 groups on the basis of preimplantation pulmonary vascular resistance: low ( $<5$ Wood units) $(\mathrm{n}=182)$ and high $(\geq 5$ Wood units $)(\mathrm{n}=45)$. Postimplantation and posttransplantation outcomes were compared between the groups.

Results: Pulmonary vascular resistance in the high resistance group decreased significantly during left ventricular assist device support $(P<.001)$. Posttransplantation in-hospital mortality was significantly higher in patients with high vascular resistance $(P<.05)$. However, 3 -year survival after transplantation was similar between groups $(85.0 \%$ and $79.0 \%$ for low and high vascular resistance, respectively; $P=.45$ ).

Conclusions: Continuous-flow left ventricular assist device therapy reduced pulmonary vascular resistance. Subsequent orthotopic heart transplantation in patients with significantly elevated pulmonary vascular resistance resulted in higher in-hospital mortality but similar 3-year survival. (J Thorac Cardiovasc Surg 2015;150:1352-61)

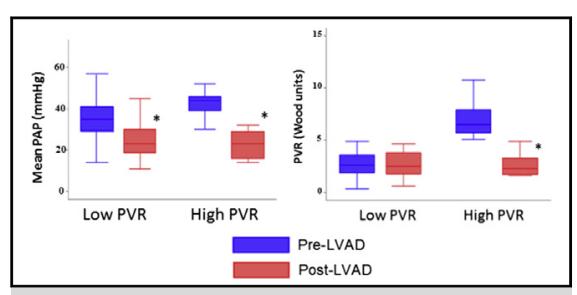

Hemodynamic parameters pre- and post-LVAD support.

\section{Central Message}

Heart transplantation in patients with pHTN results in a good outcome after LVAD support.

\section{Perspective}

CF-LVADs can reverse $\mathrm{pHTN}$ and render patients with heart failure with severe pHTN eligible for heart transplantation with reasonable survival during support. Although in-hospital mortality is higher, long-term post-transplant survival in these patients is comparable to that in patients with less PVR.

See Editorial Commentary page 1362.
Supplemental material is available online.

Pulmonary hypertension (pHTN) refractory to medical treatment is often considered a contraindication to orthotopic heart transplantation (OHT) because of an increased

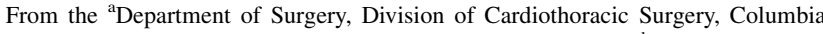
University, College of Physician and Surgeons, New York, NY; ${ }^{\mathrm{b} C o l u m b i a}$ University, New York, NY; Departments of ${ }^{\mathrm{c}}$ Medicine Cardiology and ${ }^{\mathrm{d}}$ Surgery, Columbia University, College of Physicians and Surgeons, New York, NY.

Read at the 95th Annual Meeting of The American Association for Thoracic Surgery, Seattle, Washington, April 25-29, 2015.

Received for publication March 10, 2015; revisions received June 15, 2015; accepted for publication July 3, 2015; available ahead of print Aug 5, 2015. risk of right ventricular heart failure in the immediate postoperative period. ${ }^{1}$ However, secondary pHTN has developed in approximately two thirds of transplant candidates at the time of evaluation. ${ }^{2}$ It is well known that in certain cases pHTN can be reversed with medical treatment (eg, sodium nitroprusside, milrinone, inhaled nitric oxide, and prostaglandin $\mathrm{I}_{2}$ inhibitor), and these patients are

\footnotetext{
Address for reprints: Masaki Tsukashita, MD, PhD, Division of Cardiothoracic Surgery, New York Presbyterian Hospital/Columbia University Medical Center, Milstein Hospital Building 7GN-435, New York, NY 10032 (E-mail: mt2993@cumc. columbia.edu). 0022-5223/\$36.00

Copyright (C) 2015 by The American Association for Thoracic Surgery http://dx.doi.org/10.1016/j.jtcvs.2015.07.012
} 


$$
\begin{aligned}
& \text { Abbreviations and Acronyms } \\
& \begin{aligned}
& \text { CF }=\text { continuous flow } \\
& \text { CO }=\text { cardiac output } \\
& \text { LVAD }=\text { left ventricular assist device } \\
& \text { OHT }=\text { orthotopic heart transplantation } \\
& \text { PAP }=\text { pulmonary artery pressure } \\
& \text { PCWP }=\text { pulmonary capillary wedge pressure } \\
& \text { pHTN }=\text { pulmonary hypertension } \\
& \text { PVR }=\text { pulmonary vascular resistance } \\
& \text { TPG }=\text { transpulmonary pressure gradient } \\
& \text { WU }=\text { Wood units }
\end{aligned}
\end{aligned}
$$

considered to have reversible pHTN. In contrast, some cases cannot be readily reversed by these pharmacologic treatments and are considered to have fixed or irreversible pHTN. ${ }^{3}$ The physiologic mechanism underlying reversibility has not been fully elucidated.

Previous studies have demonstrated that left ventricular assist device (LVAD) implantation can decrease pulmonary vascular resistance (PVR) by unloading the left ventricle, reducing filling pressures, and augmenting cardiac output (CO), and can therefore render even certain patients with pHTN refractory to medical treatment eligible for OHT..$^{4-9}$ However, these were mostly small studies that combined various types of LVAD devices used (pulsatile and continuous flow $[\mathrm{CF}]$ ). Given the shortage of donor organs, it is particularly important to investigate whether contemporary LVAD implantation can reverse pHTN, to what extent if it does so, and whether such reversal affects patients' eligibility for heart transplantation and the posttransplant outcomes. Therefore, we investigated the effect of CF-LVAD support on the reversal of pHTN and analyzed post-OHT outcomes in patients with an LVAD and preexisting elevated PVR.

\section{MATERIALS AND METHODS}

From March 2004 to December 2013, 340 patients at Columbia University underwent CF-LVAD insertion. Of these patients, 256 were potential heart transplantation candidates. Pre-LVAD right heart catheterization data were available for analysis in 227 of 256 patients. Clinical records of those 227 patients, including demographics, right heart catheterization data (pre-LVAD, post-LVAD, and post-OHT), intraoperative data regarding LVAD insertion and OHT, and postoperative data, were retrospectively reviewed. The Columbia University Institutional Review Board approved this study. The requirement for informed consent was waived because of the retrospective nature of the study.

\section{Right Heart Catheterization}

Hemodynamic variables, including systemic blood pressure, central venous pressure $(\mathrm{mm} \mathrm{Hg})$, pulmonary artery pressure (PAP) $(\mathrm{mm} \mathrm{Hg})$, mean pulmonary capillary wedge pressure (PCWP) ( $\mathrm{mm} \mathrm{Hg}$ ), transpulmonary pressure gradient (TPG) $(\mathrm{mm} \mathrm{Hg}$, calculated as mean PAP$\mathrm{PCWP})$, and $\mathrm{CO}(\mathrm{L} / \mathrm{min}$ ) were recorded. $\mathrm{CO}$ and mixed venous oxygen saturation were obtained using a continuous $\mathrm{CO}$ pulmonary artery catheter and confirmed using measured oxygen tension and manual calculation of
CO. PVR (Wood units [WU]) was calculated as TPG/CO. Right ventricular stroke work index $\left(\mathrm{g} \cdot \mathrm{m} / \mathrm{m}^{2} /\right.$ beat $)$ was calculated as stroke volume index $\times$ (mean PAP-central venous pressure $) \times 0.0136$. When PVR was greater than 3.0 and the patient's hemodynamic state was deemed to tolerate it, a pulmonary vasodilator challenge was performed using sodium nitroprusside, milrinone, or inhaled nitric oxide. If pulmonary vasodilator challenge was performed, the hemodynamic parameters obtained under those medications were used for this analysis, because those were considered to represent intrinsic pulmonary vascular elasticity. PreLVAD hemodynamic variables were acquired immediately before LVAD implantation. Post-LVAD hemodynamic variables were acquired at a time chosen at the discretion of the heart failure cardiologists. PostOHT right heart catheterizations were performed at 1, 2, 4, and 6 weeks; 2, 3, and 6 months; and 1, 2, 3, 4, and 5 years after OHT for all survivors. Patients were divided into 2 groups according to their postpharmacologic challenge PVR scores. A total of 182 patients had low PVR ( $<5 \mathrm{WU})$, and 45 patients had high PVR ( $\geq 5 \mathrm{WU})$.

\section{Management of Pulmonary Hypertension}

On the basis of our institutional criteria, patients with PVR 6 WU or more despite pulmonary vasodilators are excluded from OHT. These patients receive pulmonary vasodilator therapy and, if indicated, undergo LVAD implantation as destination therapy. During LVAD support, vasodilator therapy is continued, and PVR is monitored with serial right heart catheterization studies. If the PVR is decreased, the patient is reconsidered for OHT. PVR continues to be monitored while the patient is on the waiting list. Patients with low pre-LVAD PVR also underwent post-LVAD right heart catheterization if right ventricular dysfunction or device thrombosis developed. Donor hearts for these patients are selected with special attention to size and sex matching.

\section{Statistical Analysis}

Categoric variables are presented as proportions, and continuous variables are expressed as the mean \pm standard deviation for parametric analysis and as the median with interquartile range for nonparametric analysis. Differences between groups were analyzed using Pearson's chi-square test for categoric variables and the Kruskal-Wallis test for nonparametric analysis of continuous and ordinal variables. Actuarial survival during LVAD support and 3-year survival after OHT were assessed by Kaplan-Meier analysis, and the log-rank test was used for comparisons between groups. Univariate logistic regression was used to analyze the potential factors affecting early survival, and variables tested in the univariate analysis with $P$ value less than .2 were entered into the multivariate logistic regression. The statistical analyses were performed with STATA 13.1 (StataCorp LP, College Station, Tex).

\section{RESULTS \\ Patient Characteristics and Hemodynamic Data before Left Ventricular Assist Device Insertion}

The patients' characteristics before LVAD insertion showed that patients in the high PVR group were more likely to be female $(P<.05)$ and to have lower body surface area $(P<.01)$ than the patients in the low PVR groups (Table 1). There was no statistical difference in heart failure cause, medical history, preoperative dependence on mechanical ventilation, or preoperative need for inotropes or intra-aortic balloon pump between groups. Patients with high PVR were more likely to have undergone mitral or tricuspid valve surgery $(P<.01)$. The use of preoperative 
TABLE 1. Pre-left ventricular assist device patient characteristics and hemodynamic data

\begin{tabular}{|c|c|c|c|c|}
\hline Variables & All patients & Low PVR & High PVR & $\begin{array}{c}P \\
\text { value }\end{array}$ \\
\hline \multicolumn{5}{|l|}{ Basic patient characteristics } \\
\hline Patients (n) & 227 & 182 & 45 & \\
\hline Age (y) & $53.4 \pm 12.5$ & $53.3 \pm 12.5$ & $53.8 \pm 12.3$ & .82 \\
\hline Female sex & $41(18.1 \%)$ & $28(15.4 \%)$ & $13(28.9 \%)$ & .035 \\
\hline BMI & $26.4 \pm 5.3$ & $26.5 \pm 5.3$ & $26.2 \pm 5.4$ & .7 \\
\hline BSA & $1.97 \pm 0.3$ & $1.99 \pm 0.26$ & $1.87 \pm 0.25$ & .005 \\
\hline \multicolumn{5}{|l|}{ Cause of HF } \\
\hline $\mathrm{ICM}$ & $83(36.6 \%)$ & $68(37.4 \%)$ & $15(33.3 \%)$ & .39 \\
\hline DCM & $129(56.8 \%)$ & $104(57.1 \%)$ & $25(55.6 \%)$ & \\
\hline Others & $15(6.6 \%)$ & $10(5.5 \%)$ & $5(11.1 \%)$ & \\
\hline CAD & $89(39.2 \%)$ & $73(40.1 \%)$ & $16(35.6 \%)$ & .58 \\
\hline MI & $73(32.2 \%)$ & $59(32.4 \%)$ & $14(31.1 \%)$ & .87 \\
\hline CVA & $27(11.9 \%)$ & $18(9.9 \%)$ & $9(20.0 \%)$ & .06 \\
\hline DM & $75(33.0 \%)$ & $64(35.2 \%)$ & $11(24.4 \%)$ & .17 \\
\hline HTN & $104(45.8 \%)$ & $81(44.5 \%)$ & $23(51.1 \%)$ & .43 \\
\hline PVD & $15(6.6 \%)$ & $10(5.5 \%)$ & $5(11.1 \%)$ & .17 \\
\hline Smoking & $93(41.0 \%)$ & $74(40.7 \%)$ & $19(42.2 \%)$ & .85 \\
\hline COPD & $17(7.5 \%)$ & $11(6.0 \%)$ & $6(13.3 \%)$ & .1 \\
\hline Preoperative inotropes & $200(88.1 \%)$ & $159(87.4 \%)$ & $41(91.1 \%)$ & .49 \\
\hline Preoperative MCS & $22(9.7 \%)$ & $18(9.9 \%)$ & $4(8.9 \%)$ & .84 \\
\hline Preoperative IABP & $58(25.6 \%)$ & $48(26.4 \%)$ & $10(22.2 \%)$ & .57 \\
\hline $\begin{array}{l}\text { Preoperative ventilator } \\
\text { support }\end{array}$ & $7(3.2 \%)$ & $6(3.3 \%)$ & $1(2.5 \%)$ & .71 \\
\hline $\begin{array}{c}\text { Previous cardiac } \\
\text { surgery }\end{array}$ & $42(18.5 \%)$ & $29(15.9 \%)$ & $13(28.9 \%)$ & .045 \\
\hline CABG & $34(15.0 \%)$ & $27(14.8 \%)$ & $7(15.6 \%)$ & .9 \\
\hline Mitral valve & $13(5.7 \%)$ & $6(3.3 \%)$ & $7(15.6 \%)$ & .002 \\
\hline Tricuspid valve & $3(1.3 \%)$ & $0(0.0 \%)$ & $3(6.7 \%)$ & .0001 \\
\hline Aortic valve & $4(1.8 \%)$ & $4(2.2 \%)$ & $0(0.0 \%)$ & .32 \\
\hline Congenital & $2(0.90 \%)$ & $1(0.6 \%)$ & $1(2.2 \%)$ & .28 \\
\hline \multicolumn{5}{|l|}{ Hemodynamic data } \\
\hline $\operatorname{LVEF}(\%)$ & $15.2 \pm 6.1$ & $15.2 \pm 6.3$ & $15.2 \pm 5.2$ & .7 \\
\hline Mean PAP (mm Hg) & $36.2 \pm 10.4$ & $34.7 \pm 9.8$ & $42.3 \pm 10.4$ & .0001 \\
\hline PCWP (mm Hg) & $24.1 \pm 8.5$ & $24.3 \pm 8.7$ & $23.0 \pm 7.9$ & .56 \\
\hline TPG (mm Hg) & $12.1 \pm 6.5$ & $10.3 \pm 5.2$ & $19.2 \pm 6.4$ & .0001 \\
\hline $\mathrm{CO}(\mathrm{L} / \mathrm{min})$ & $3.30 \pm 1.02$ & $3.50 \pm 0.98$ & $2.57 \pm 0.83$ & .0001 \\
\hline PVR (wood units) & $3.59 \pm 2.23$ & $2.71 \pm 1.12$ & $7.13 \pm 2.09$ & .0001 \\
\hline $\operatorname{RVSWI}\left(\mathrm{g} \cdot \mathrm{m} / \mathrm{m}^{2} /\right.$ beat $)$ & $6.98 \pm 3.55$ & $7.00 \pm 3.54$ & $6.93 \pm 3.61$ & .81 \\
\hline \multicolumn{5}{|c|}{$\begin{array}{l}\text { Data are expressed as means } \pm \text { standard deviations or as } \mathrm{n}(\%) \text {. Differences were } \\
\text { considered significant at } P<.05 \text {, and these values are listed in bold. } B M I \text {, Body } \\
\text { mass index; } B S A \text {, body surface area }\left(\mathrm{m}^{2}\right) ; C A B G \text {, coronary artery bypass grafting; } \\
C A D \text {, coronary artery disease; } C O \text {, cardiac output; } C O P D \text {, chronic obstructive pul- } \\
\text { monary disease; } C V A \text {, cerebrovascular accident; } D C M \text {, dilated cardiomyopathy; } \\
D M \text {, diabetes mellitus; } H F \text {, heart failure; } H T N \text {, hypertension; } I A B P \text {, intra-aortic } \\
\text { balloon pump; } I C M \text {, ischemic cardiomyopathy; } L V E F \text {, left ventricular ejection frac- } \\
\text { tion; } M C S \text {, mechanical circulatory support; } M I \text {, myocardial infarction; } P A P \text {, pulmo- } \\
\text { nary artery pressure; } P C W P \text {, pulmonary capillary wedge pressure; } P V D \text {, peripheral } \\
\text { vascular disease; } P V R \text {, pulmonary vascular resistance; } R V S W I \text {, right ventricular } \\
\text { stroke work index; } T P G \text {, transpulmonary pressure gradient. }\end{array}$} \\
\hline
\end{tabular}

mechanical circulatory support was not different between groups $(P=.84)$.

There was a significant difference in PVR between groups $(2.71 \pm 1.12 \mathrm{WU}$ and $7.13 \pm 2.09 \mathrm{WU}$ for the low PVR and high PVR groups, respectively, $P<.001$ ). The high PVR group included patients with severe pHTN, ranging from 5.07 to 14.38 WU. In the high PVR group, the mean PAP was significantly higher than in the low PVR group $(34.7 \pm 9.8 \mathrm{~mm} \mathrm{Hg}$ and $42.3 \pm$ $10.4 \mathrm{~mm} \mathrm{Hg}$ for the low PVR and high PVR groups, respectively, $P<.001)$. TPG was also higher $(10.3 \pm$ $5.2 \mathrm{~mm} \mathrm{Hg}$ and $19.2 \pm 6.4 \mathrm{~mm} \mathrm{Hg}$ for the low PVR and high PVR groups, respectively, $P<.001)$. In contrast, $\mathrm{CO}$ was significantly lower in the high PVR group than in the low PVR group $(3.50 \pm 0.98 \mathrm{~L} / \mathrm{min}$ and $2.57 \pm 0.83$ $\mathrm{L} / \mathrm{min}$ for the low PVR and high PVR groups, respectively, $P<.001)$. There was no statistical difference in PCWP $(P=.56)$ or right ventricular stroke work index $(P=.81)$ between groups.

\section{Intraoperative and Postoperative Data at Left Ventricular Assist Device Implantation}

CF-LVADs used were the HeartMate II (Thoratec Corp, Pleasanton, Calif), HeartWare (HeartWare Inc, Framingham, Mass), DuraHeart (Terumo Heart Inc, Ann Arbor, Mich), DeBakey (MicroMed Cardiovascular, Inc, Houston, Tex), VentrAssist (Ventracor Limited, Chatswood, Australia), or Jarvik 2000 (Jarvik Heart, Inc, New York, $\mathrm{NY}$ ). There was no statistical difference in cardiopulmonary bypass time or the need for aortic crossclamp between groups (Table 2). The number of patients for whom each type of LVAD was implanted is summarized in Table 2. The HeartMate II device was used for most patients $(81.1 \%)$, although a higher rate of use of the HeartWare device in the high PVR group was noted $(7.1 \%$ and $15.6 \%$ for the low PVR and high PVR groups, respectively, $P<.01)$. Concomitant valve procedures were performed as follows: aortic valve procedures in 32 patients $(14.1 \%)$, mitral valve procedures in 26 patients $(11.5 \%)$, and tricuspid procedures in 55 patients $(24.2 \%)$. There was no statistical difference in the proportion of patients who underwent concomitant valve procedures between groups.

Length of intensive care unit stay, in-hospital mortality, and incidence of adverse events were comparable between groups after LVAD implantation. Right ventricular assist device implantation was needed in $7.7 \%$ of the low PVR group and $4.4 \%$ of the high PVR group $(P=.45)$. One-year survival during LVAD support was $81.9 \%$ and $90.3 \%$ in the low PVR and high PVR groups, respectively $(P=.16)$. Figure 1 shows the Kaplan-Meier survival curve during LVAD support (transplant recipients were censored). There was no difference in survival during LVAD support between groups $(P=.14)$, and there was no statistical difference in the percentage of patient outcomes for OHT, cardiac recovery, or ongoing LVAD support $(P=.24)$. In the low PVR group, 120 patients $(65.9 \%)$ underwent heart transplant, 2 patients $(1.1 \%)$ recovered and underwent LVAD explant, and 30 patients $(16.5 \%)$ were on the waiting list at the time of last 
TABLE 2. Intraoperative and postoperative data for left ventricular assist device insertion

\begin{tabular}{|c|c|c|c|c|}
\hline Variables & All patients $(n=227)$ & Low PVR $(n=182)$ & High PVR $(n=45)$ & $P$ value \\
\hline \multicolumn{5}{|l|}{ Intraoperative data } \\
\hline CPB time (min) & $89.5 \pm 50.3$ & $88.8 \pm 52.0$ & $92.5 \pm 42.8$ & .36 \\
\hline Aortic crossclamp & $39(17.2 \%)$ & $29(15.9 \%)$ & $10(22.2 \%)$ & .32 \\
\hline \multicolumn{5}{|l|}{ Device type } \\
\hline HeartMate II (Thoratec Corp, Pleasanton, Calif) & $184(81.1 \%)$ & $151(83.0 \%)$ & $33(73.3 \%)$ & \multirow{6}{*}{.009} \\
\hline HeartWare (HeartWare Inc, Framingham, Mass) & $20(8.8 \%)$ & $13(7.1 \%)$ & $7(15.6 \%)$ & \\
\hline VentrAssist (Ventracor Limited, Chatswood, Australia) & $8(3.5 \%)$ & $4(2.2 \%)$ & $4(8.9 \%)$ & \\
\hline DeBakey (MicroMed Cardiovascular, Inc, Houston, Tex) & $6(2.6 \%)$ & $6(3.3 \%)$ & $0(0.0 \%)$ & \\
\hline Dura Heart (Terumo Heart Inc, Ann Arbor, Mich) & $8(3.5 \%)$ & $8(4.4 \%)$ & $0(0.0 \%)$ & \\
\hline Jarvik 2000 (Jarvik Heart, Inc, New York, NY) & $1(0.4 \%)$ & $0(0.0 \%)$ & $1(2.2 \%)$ & \\
\hline \multicolumn{5}{|l|}{ Concomitant procedure } \\
\hline Aortic valve & $32(14.1 \%)$ & $24(13.2 \%)$ & $8(17.8 \%)$ & .43 \\
\hline Mitral valve & $26(11.5 \%)$ & $18(9.9 \%)$ & $8(17.8 \%)$ & .14 \\
\hline Tricuspid valve & $55(24.2 \%)$ & $46(25.3 \%)$ & $9(20.0 \%)$ & .46 \\
\hline \multicolumn{5}{|l|}{ Postoperative data } \\
\hline iNO use & $82(36.1 \%)$ & $60(33.0 \%)$ & $22(48.9 \%)$ & .046 \\
\hline ICU stay (d) [IQR] & $7[5-11]$ & $7[5-10]$ & 7 [6-12] & .18 \\
\hline In-hospital mortality & $15(6.6 \%)$ & $13(7.1 \%)$ & $2(4.4 \%)$ & .51 \\
\hline CVA & $12(5.3 \%)$ & $9(5.0 \%)$ & $3(6.7 \%)$ & .64 \\
\hline $\mathrm{HD} / \mathrm{CVVH}$ & $22(9.7 \%)$ & $20(11.0 \%)$ & $2(4.4 \%)$ & .18 \\
\hline Tracheotomy & $6(2.6 \%)$ & $4(2.2 \%)$ & $2(4.4 \%)$ & .4 \\
\hline RVAD support & $16(7.1 \%)$ & $14(7.7 \%)$ & $2(4.4 \%)$ & .45 \\
\hline Bleeding/take-back & $43(18.9 \%)$ & $37(20.3 \%)$ & $6(13.3 \%)$ & .28 \\
\hline \multicolumn{5}{|l|}{ Bridge to } \\
\hline OHT & $150(66.1 \%)$ & $120(65.9 \%)$ & $30(66.7 \%)$ & \multirow{3}{*}{.24} \\
\hline Recovery & $2(0.9 \%)$ & $2(1.1 \%)$ & $0(0.0 \%)$ & \\
\hline Ongoing support & $42(18.5 \%)$ & $30(16.5 \%)$ & $12(26.7 \%)$ & \\
\hline
\end{tabular}

Differences were considered significant at $P<.05$, and these values are listed in bold. $C P B$, Cardiopulmonary bypass; $C V A$, cerebrovascular accident; $H D / C V V H$, hemodialysis/ continuous veno-venous hemofiltration; $I C U$, intensive care unit; $i N O$, inhaled nitric oxide; $I Q R$, interquartile range; $O H T$, orthotopic heart transplantation; $P V R$, pulmonary vascular resistance; $R V A D$, right ventricular assist device.

follow-up. In the high PVR group, 30 patients (66.7\%) underwent heart transplant and 12 patients $(26.7 \%)$ were on LVAD support. In the high PVR group, 1 patient died of respiratory arrest, 1 patient died of cerebrovascular accident, and 1 patient died of multiorgan failure after device exchange.

\section{Changes Over Time in Pulmonary Vascular Resistance}

After LVAD implantation, PVR in the high PVR group decreased significantly $(7.13 \pm 2.09 \mathrm{WU}$ to $2.82 \pm 1.46$ WU, $P<.001)$ to a level similar that in the low PVR group $(2.70 \pm 1.20 \mathrm{WU}, P=.91)$ and remained low after heart transplantation (Figure 2). No patient in the high PVR group had the PVR increased after the LVAD was implanted. Figure E1 shows the change in each hemodynamic variable pre- and post-LVAD. In the high PVR group, mean PAP, PCWP, and TPG were reduced significantly, and CO improved. Although the median interval between the LVAD implantation and the post-LVAD hemodynamic measurement was lower in the high PVR group, there was no statistical difference $(P=.3)$ (363 days [interquartile range, 140-566] in the low PVR group and 152 days [interquartile range, 96-438] in the high PVR group). The prevalence of chronic pulmonary vasodilator treatment (eg, sildenafil or tadalafil) at the time of the post-LVAD hemodynamic measurement was $19 \%$ and $40 \%$ in the low PVR and high PVR groups, respectively $(P=.17)$.

\section{Intraoperative and Postoperative Data at Orthotopic Heart Transplantation Surgery}

For 150 patients who underwent heart transplant, donor data (age, ABO compatibility, and donor-recipient weight ratio) and intra- and postoperative data were analyzed (Table 3). There was no statistical difference in donor characteristics between groups. For those who underwent heart transplantation, the duration of LVAD support was not significantly different between groups (median, 211 and 229.5 days for low PVR and high PVR groups, respectively, $P=.53$ ). Cardiopulmonary bypass time and donor heart ischemic time were similar between groups. There was no significant difference in the incidence of major complications, such as cerebrovascular accident, renal failure requiring hemodialysis, and respiratory failure between groups. The mean follow-up period after OHT was $3.5 \pm$ 2.4 years (range, 1 month to 9.3 years). In-hospital mortality after OHT was significantly higher in the high PVR than in 


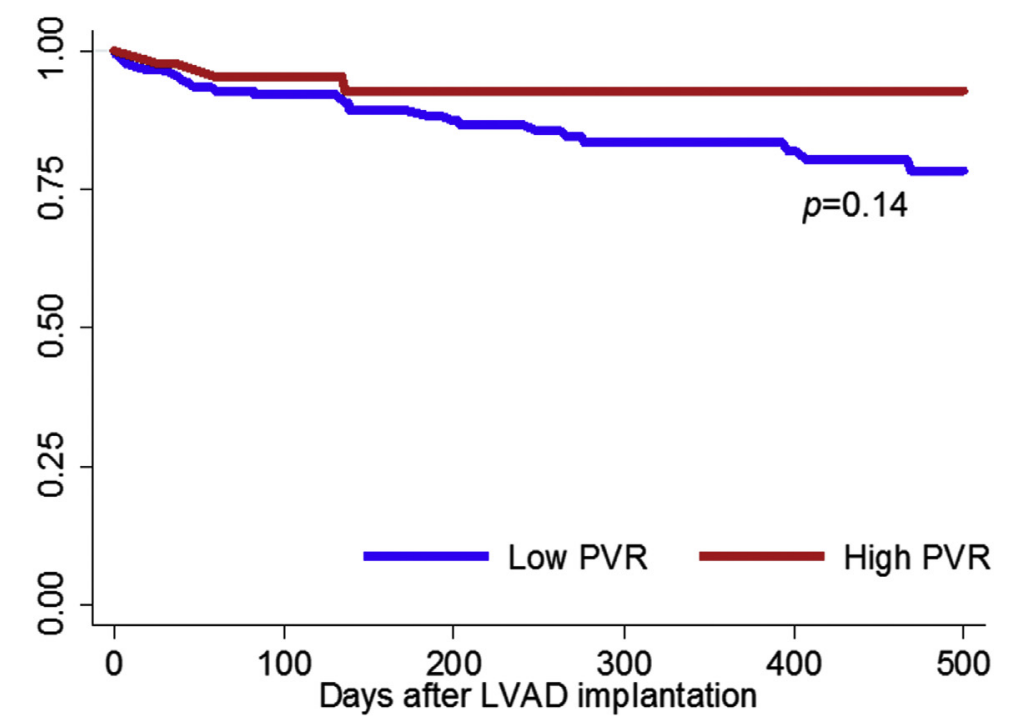

$\begin{gathered}\text { Number at risk } \\
\text { Low PVR }\end{gathered} 182$
\begin{tabular}{|ccccccc|} 
High PVR & 45 & 140 & 104 & 72 & 52 & 37 \\
\hline & 40 & 28 & 18 & 14 & 11 \\
\hline & 100 days & 200 days & 300 days & 400 days & 500 days \\
\hline Low & $95 \% \mathrm{Cl})$ & $(95 \% \mathrm{Cl})$ & $(95 \% \mathrm{Cl})$ & $(95 \% \mathrm{Cl})$ & $(95 \% \mathrm{Cl})$ \\
\hline PVR & $(86.3 \%-95.0 \%)$ & $(80.9 \%-91.6 \%)$ & $(76.0 \%-88.7 \%)$ & $(74.2 \%-87.7 \%)$ & $(69.1 \%-85.3 \%)$ \\
\hline High & $95.3 \%$ & $92.5 \%$ & $92.5 \%$ & $92.5 \%$ & $92.5 \%$ \\
PVR & $(82.5 \%-98.8 \%)$ & $(78.4 \%-97.5 \%)$ & $(78.4 \%-97.5 \%)$ & $(78.4 \%-97.5 \%)$ & $(78.4 \%-97.5 \%)$ \\
\hline
\end{tabular}

FIGURE 1. Kaplan-Meier survival curve during LVAD support. Survival at each time point is shown with $95 \%$ confidence interval in the table. $C I$, Confidence interval; $L V A D$, left ventricular assist device; $P V R$, pulmonary vascular resistance.

the low PVR group $(5.8 \%$ and $20.7 \%$ in the low PVR and high PVR groups, respectively, $P<.05$ ). Of 6 deaths in the high PVR group, 4 patients died as a result of primary graft failure (defined as the need for mechanical circulatory support in the immediate post-transplant period). All 4 patients needed a biventricular assist device. There was only 1 patient who died of primary graft failure in the low PVR group. There was no statistical difference in the dosage of post-OHT inotropes, blood transfusions, and the length of hospital stay between groups (data not shown). All causes of post-OHT mortality during follow-up are shown in Table E1. The Kaplan-Meier 3-year survival curve after OHT is shown in Figure 3. The log-rank test showed no statistical difference in survival between groups $(P=.26)$. The survival at 3 years post-OHT was $85.0 \%$ and $79.0 \%$ for the low PVR and high PVR groups, respectively $(P=.45)$.

Univariate and multivariate logistic regression analyses were performed for 30-day post-OHT survival (Table 4). The multivariate analysis revealed that pre-LVAD PVR 5 or greater was strongly associated with early mortality (odds ratio, 5.99; 95\% confidence interval, 1.25-28.9;
$P<.05)$. Post-LVAD PVR was not associated with shortterm mortality after OHT.

\section{DISCUSSION}

The present study is a retrospective, single-institution study on patients with end-stage heart failure who underwent LVAD insertion that especially focused on preexisting pHTN. To our knowledge, this is the largest study ever reported with regard to the effects of preexisting pHTN on OHT outcomes in patients bridged with CF-LVAD. In this study, we found 3 interesting findings: (1) PVR decreased after LVAD implantation even in patients with severe pHTN refractory to pulmonary vasodilators; (2) despite the improvement in PVR, patients with high PVR still had higher early mortality; and (3) the long-term survival (mean follow-up 3.5 years) was not different among groups.

Secondary pHTN due to an elevation in left ventricular filling pressure and subsequent increase in PVR develop in approximately two thirds of patients with heart failure and reduced ejection fraction. ${ }^{2}$ Long-standing elevation of PCWP results in pulmonary vascular disease with vasoconstriction and remodeling of the pulmonary arterial bed, 


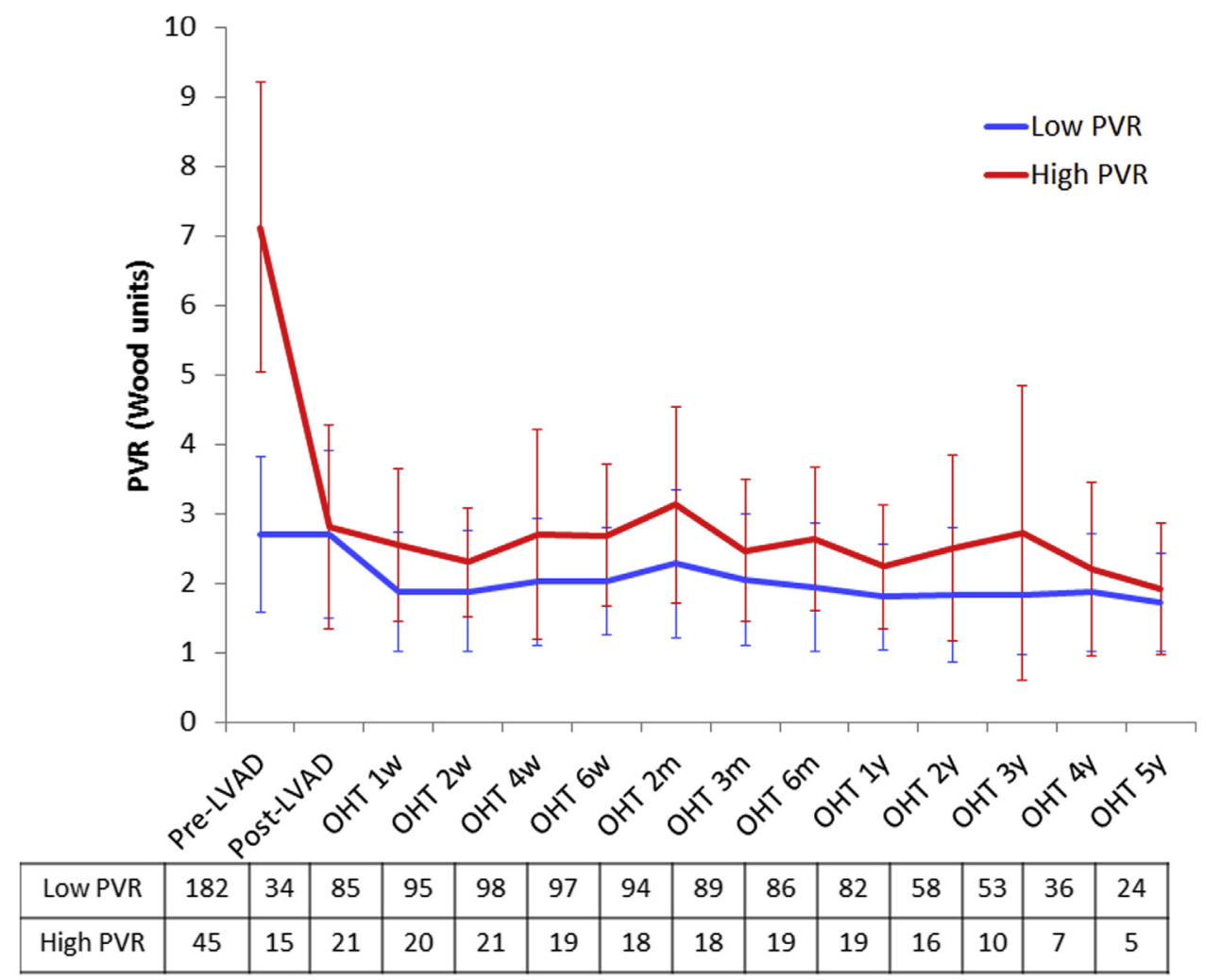

FIGURE 2. Chronologic change in PVR after LVAD insertion. Numbers in the table represent the number of patients who underwent right heart catheterization at each time point. $L V A D$, Left ventricular assist device; $O H T$, orthotopic heart transplantation; $P V R$, pulmonary vascular resistance.

which manifests as increased PVR and TPG. This phenomenon was also shown in our study. Pre-LVAD right heart catheterization data showed no statistical difference in PCWP, regardless of the severity of PVR. This observation suggests that once heart failure reached the end stage, the elevation of PAP is caused not by further elevation of PCWP but by the elevation of TPG secondary to pulmonary vascular remodeling. The presence of elevated PVR is

TABLE 3. Intraoperative and postoperative data for orthotopic heart transplantation

\begin{tabular}{|c|c|c|c|c|}
\hline Variables & All patients $(n=150)$ & Low PVR $(n=120)$ & $\operatorname{High}$ PVR $(n=30)$ & $P$ value \\
\hline \multicolumn{5}{|l|}{ Donor data } \\
\hline Age & $29.7 \pm 9.5$ & $29.2 \pm 9.2$ & $31.8 \pm 11.0$ & .38 \\
\hline ABO identical & $88.5 \%$ & $89.0 \%$ & $86.7 \%$ & .72 \\
\hline $\mathrm{ABO}$ compatible & $11.5 \%$ & $11.0 \%$ & $13.3 \%$ & \\
\hline Donor/recipient weight & $0.99 \pm 0.17$ & $0.98 \pm 0.16$ & $1.03 \pm 0.18$ & .19 \\
\hline \multicolumn{5}{|l|}{ Recipient data } \\
\hline LVAD duration $(\mathrm{d})$ [IQR] & 219 [110-359] & $211[105.5-356]$ & 229.5 [134-397] & .53 \\
\hline \multicolumn{5}{|l|}{ Intraoperative data } \\
\hline CPB time (min) & $176 \pm 54$ & $174 \pm 47$ & $184 \pm 74$ & .90 \\
\hline Ischemic time (min) & $189 \pm 51$ & $188 \pm 50$ & $192 \pm 54$ & .80 \\
\hline \multicolumn{5}{|l|}{ Postoperative data } \\
\hline iNO use & $49(33.8 \%)$ & $37(31.1 \%)$ & $13(44.8 \%)$ & .16 \\
\hline In-hospital mortality & $13(8.7 \%)$ & $7(5.8 \%)$ & $6(20.0 \%)$ & .014 \\
\hline CVA & $8(5.4 \%)$ & $6(5.1 \%)$ & $2(6.7 \%)$ & .73 \\
\hline $\mathrm{HD} / \mathrm{CVVH}$ & $24(16.2 \%)$ & $19(16.1 \%)$ & $5(16.7 \%)$ & .94 \\
\hline Tracheotomy & $10(6.8 \%)$ & $8(6.8 \%)$ & $2(6.7 \%)$ & .98 \\
\hline Bleeding & $32(21.6 \%)$ & $25(21.2 \%)$ & $7(23.3 \%)$ & .80 \\
\hline Primary graft failure & $12(8.1 \%)$ & $8(6.8 \%)$ & $4(13.3 \%)$ & .24 \\
\hline
\end{tabular}

Differences were considered significant at $P<.05$, and these values are listed in bold. $C P B$, Cardiopulmonary bypass; $C V A$, cerebrovascular accident; $H D / C V V H$, hemodialysis $/$ continuous veno-venous hemofiltration; $i N O$, inhaled nitric oxide; $I Q R$, interquartile range; $L V A D$, left ventricular assist device; $P V R$, pulmonary vascular resistance; $A B O$, blood type. 


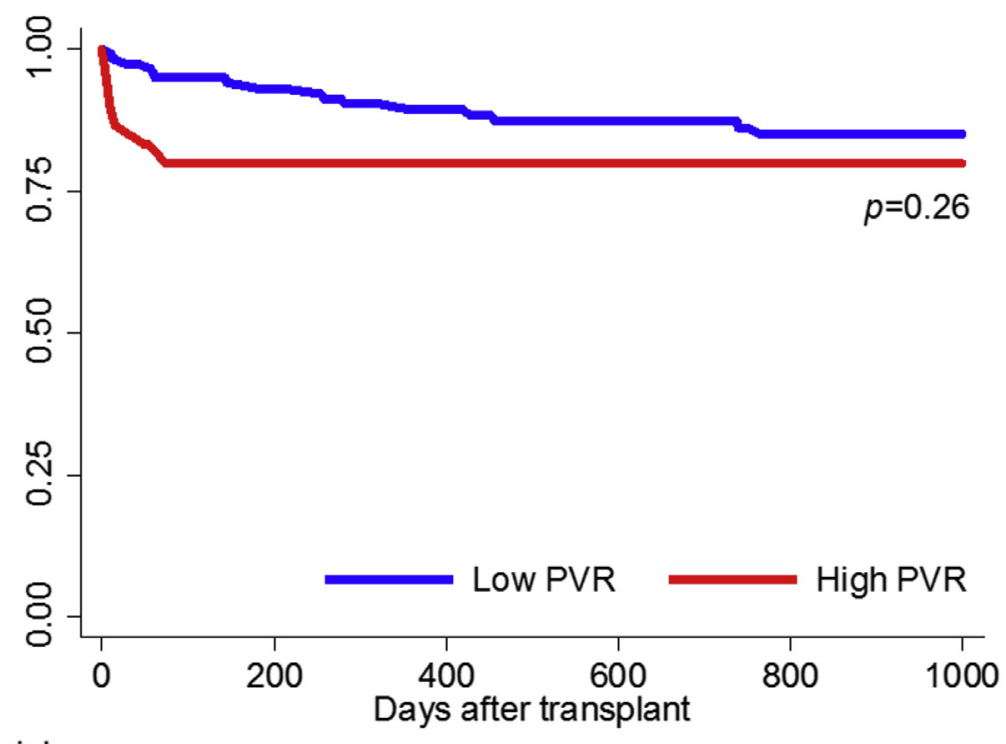

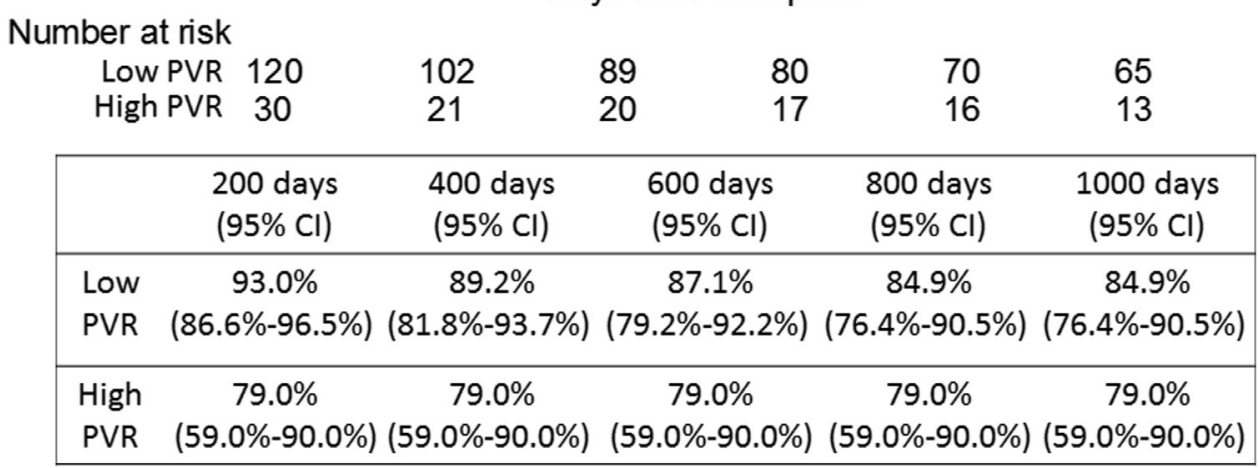

FIGURE 3. Kaplan-Meier survival curve after heart transplantation. Survival at each time point is shown with $95 \%$ confidence interval in the table. $C I$, Confidence interval; $P V R$, pulmonary vascular resistance.

found in approximately one third of patients with heart failure with reduced ejection fraction and is often associated with mortality and morbidity. ${ }^{10}$

Secondary pHTN can be treated by pulmonary vasodilators, such as nitroglycerine, prostaglandins, milrinone, sildenafil, and inhaled nitric oxide. These pharmacologic agents have improved pulmonary hemodynamics and outcomes of OHT. ${ }^{11-14}$ However, pHTN may not be readily reversible and may even be irreversible by pharmacologic treatment, and for patients with progressive, decompen7 sated heart failure, long-term administration of vasodilators are of limited use because of the risk of systemic hypotension. OHT is the most effective therapeutic alternative for end-stage heart failure. However, OHT in the patients with fixed pHTN is contraindicated because of unacceptably high risks of right ventricular failure and the associated high mortality rate. ${ }^{15}$ Current guidelines recommend that PVR greater than $5 \mathrm{WU}$, indexed PVR greater than $6 \mathrm{WU} / \mathrm{m}^{2}$, or TPG greater than 16 to $20 \mathrm{~mm} \mathrm{Hg}$, despite an aggressive challenge with 1 or more vasodilators or inotropic agents, represents a relative contraindication to OHT. $^{16}$
LVAD therapy is one treatment option for pHTN associated with heart failure. By unloading the left ventricle, it reduces the postcapillary downstream pressure, and, with time, it can lower TPG and PVR. In the current study, we found that LVAD support reduced PVR significantly. After LVAD insertion, PVR in the high PVR group decreased to a level comparable to that in the low PVR group, suggesting that LVAD can reverse even severe pHTN refractory to medical treatment. PVR remained low even after OHT in survivors. The long-term survival after OHT was also comparable, regardless of pHTN severity. This observation was consistent with previous studies. ${ }^{4-7}$ Mikus and colleagues ${ }^{4}$ reported a significant reduction of mean PAP, TPG, and PVR in 27 patients with preexisting fixed pHTN with LVAD support. Etz and colleagues ${ }^{5}$ also showed a similar reduction of PVR in 10 patients with severe $\mathrm{pHTN}$ refractory to medical treatment undergoing LVAD insertion with no significant increase in PAP, TPG, or PVR after the heart transplantation.

Although the time interval between LVAD implantation and post-LVAD hemodynamic measurement in our study is variable, the PVR in the high PVR group decreased as 
TABLE 4. Univariate and multivariate logistic regression analyses of the short-term survival post-orthotopic heart transplantation

\begin{tabular}{|c|c|c|c|c|c|c|}
\hline \multirow[b]{2}{*}{ Variables } & \multicolumn{3}{|c|}{ Univariate analysis } & \multicolumn{3}{|c|}{ Multivariate analysis } \\
\hline & OR & $95 \%$ CI & $P$ value & OR & $95 \%$ CI & $\begin{array}{c}P \\
\text { value }\end{array}$ \\
\hline Age & 1.03 & $0.96-1.10$ & .44 & & & \\
\hline Sex (male) & 1.40 & $0.16-12.2$ & .76 & & & \\
\hline BMI & 0.92 & $0.78-1.08$ & .30 & & & \\
\hline ICM & 0.76 & $0.14-4.06$ & .75 & & & \\
\hline COPD & 2.2 & $0.24-20.1$ & .49 & & & \\
\hline HTN & 3.05 & $0.57-16.2$ & .19 & 2.86 & $0.52-15.7$ & .23 \\
\hline $\begin{array}{r}\text { HeartMate II } \\
\text { (vs others) }\end{array}$ & 0.48 & $0.09-2.64$ & .40 & & & \\
\hline Preoperative MCS & 1.98 & $0.22-18.0$ & .54 & & & \\
\hline $\begin{array}{l}\text { LVAD support } \\
\text { duration }\end{array}$ & 1.002 & $0.99-1.00$ & .10 & 1.00 & $0.99-1.00$ & .72 \\
\hline $\begin{array}{l}\text { Interval between } \\
\text { post-LVAD } \\
\text { RHC and OHT }\end{array}$ & 1.006 & $0.99-1.01$ & 11 & 1.00 & 0.99-1.02 & .35 \\
\hline Pre-LVAD PVR >5 & 6.00 & $1.26-28.4$ & .02 & 5.99 & $1.25-28.9$ & .03 \\
\hline Smoking & 1.88 & $0.40-8.70$ & .42 & & & \\
\hline Post-LVAD PVR >3 & 0.58 & $0.05-6.35$ & .65 & & & \\
\hline
\end{tabular}

Differences were considered significant at $P<.05$, and these values are listed in bold. $B M I$, Body mass index; $C I$, confidence interval; $C O P D$, chronic obstructive pulmonary disease; $H T N$, hypertension; $I C M$, ischemic cardiomyopathy; $L V A D$, left ventricular assist device; $M C S$, mechanical circulatory support; $O H T$, orthotopic heart transplantation; $O R$, odds ratio; $P V R$, pulmonary vascular resistance; $R H C$, right heart catheterization.

early as 37 days post-LVAD implantation. Zimpfer and colleagues $^{8}$ reported important findings regarding time required post-LVAD implantation to see a reduction in PVR. They analyzed hemodynamic variables pre- and post-LVAD implantation ( 3 days and 6 weeks post-LVAD) in 35 patients with pHTN refractory to medical treatment. They found a significant reduction in PVR (from 5.1 preLVAD to 2.9 at the 3-day follow-up and to 2.0 at the 6-week follow-up) after LVAD implantation. Mikus and colleagues ${ }^{4}$ reported that the reduction in PVR occurs in the first 6 months of LVAD support and that longer support does not add any effect on pHTN. These data, including ours, suggest that the reduction in PVR after LVAD implantation may be seen in early-stage post-LVAD.

One of the unique aspects of this study is the severity of $\mathrm{pHTN}$. We have been aggressive in the management of endstage heart failure and have bridged patients with markedly elevated PVR to OHT. In our study, $66.7 \%$ of patients with pre-LVAD PVR 5 WU or greater reached OHT after a support interval that was comparable to that in patients with lower PVR. Post-OHT 3-year survival of these patients was $79.0 \%$, similar to survival of patients with lower PVR. These numbers are consistent with previous reports regarding OHT outcomes for patients bridged to transplantation with or without preexisting pHTN. ${ }^{17,18}$

In our study, in-hospital mortality of the high PVR group was 3-fold higher than in the low PVR group, and
pre-LVAD PVR 5 or greater was a potent predictor of early mortality after OHT. All post-OHT mortality in the high PVR group occurred while the patients were in the hospital. Alba and colleagues ${ }^{19}$ also reported a higher peritransplant mortality in the pre-LVAD fixed pHTN group than in the nonfixed pHTN group ( $18 \%$ vs $0 \%)$. Torre-Amione and colleagues ${ }^{20}$ reported on 9 patients with heart failure with secondary pHTN (TPG $>15 \mathrm{~mm} \mathrm{Hg}$ ) who underwent LVAD implantation. After LVAD support, the TPG in these patients decreased significantly and 1-year Kaplan-Meier survival curve for OHT was similar to that in patients with pre-LVAD TPG less than $15 \mathrm{~mm} \mathrm{Hg}$. However, there was 1 early mortality $(11 \%)$ due to primary graft failure in the high TPG group. Torre-Amione and colleagues also conducted an analysis of the data obtained from the Organ Procurement and Transplantation Network database, which is a large multi-institutional cohort. Of note, 30-day mortality was significantly higher in patients with elevated TPG $(13.2 \%$ vs $6.7 \%)$ than in those with lower TPG. One of the possible reasons for the higher early mortality in the high PVR group is that although PVR decreases with the aid of LVAD support, reversal of pulmonary vascular remodeling is heterogeneous or incomplete, and the pulmonary arterioles that have not been reverse remodeled may be susceptible to early postoperative insults, such as myocardial ischemia, metabolic acidosis, hypoxemia, or inflammatory response imposed by cardiopulmonary bypass, infection, or blood transfusion. Although PVR in the high PVR group was reduced significantly with LVAD support (mean, 7.1-2.8 WU) to a level comparable to that in the low PVR group, it is speculated that in a subset of patients, PVR might not have reduced to the level that the right ventricle is able to eject blood against. It is well known that the normal thin-wall right ventricle is exquisitely afterload-sensitive and cannot tolerate abrupt increases in afterload, even with mild pHTN. ${ }^{21}$ However, our study failed to demonstrate a correlation between post-LVAD PVR and early mortality after OHT. Another possibility is that because the hemodynamic data were not collected immediately before OHT, those numbers do not reflect the actual patient hemodynamics at the time of OHT. Further investigation is warranted to ascertain the cause of high early mortality post-OHT in patients with pre-LVAD pHTN.

\section{Study Limitations}

The main limitation of the present study is that this is a retrospective and nonrandomized study at a single institution. However, comparing OHT outcomes by randomizing patients with heart failure with pHTN with a group with or without LVAD support would be clinically impractical. We believe that given the paucity of data regarding the effect of preexisting pHTN on the outcome of OHT in patients bridged to transplantation, this large study provides data with statistical strength that are less biased by preoperative 
risk characteristics and types of LVAD device implanted. The second limitation is that not all patients underwent right heart catheterization after LVAD insertion or OHT surgery because of anticoagulation or a patient health condition not amenable to invasive hemodynamic study, or other reasons. It is possible that patients who did not undergo right heart catheterization and died during LVAD support or after OHT had persistently high PVR despite LV unloading. Also, the timing of hemodynamic measurement relative to LVAD implantation and OHT was not uniform and was potentially dynamic. Because of the retrospective nature of this study, survival comparisons are unadjusted comparisons.

\section{CONCLUSIONS}

LVAD therapy significantly reduced PVR even in patients with severely elevated PVR. Although the early post-OHT mortality in LVAD recipients with high PVR was high, their long-term survival was comparable to that for patients with lower PVR. For patients with end-stage heart failure who used to be deemed ineligible for OHT because of severe pHTN, LVAD therapy as a bridge to transplant may be a reasonable strategy.

\section{Conflict of Interest Statement}

Y.N. has received consulting fees from Thoratec Corp. All other authors have nothing to disclose with regard to commercial support.

You can watch a Webcast of this AATS meeting presentation by going to: http://webcast.aats.org/2015/Video/ Tuesday/04-28-15_607_0810_Tsukashita.mp4

\section{References}

1. Kirklin JK, Naftel DC, Kirklin JW, Blackstone EH, White-Williams C, Bourge RC. Pulmonary vascular resistance and the risk of heart transplantation. J Heart Transplant. 1988;7:331-6.

2. Butler J, Chomsky DB, Wilson JR. Pulmonary hypertension and exercise intolerance in patients with heart failure. J Am Coll Cardiol. 1999;34:1802-6.

3. Fang JC, DeMarco T, Givertz MM, Borlaug BA, Lewis GD, Rame JE, et al. World Health Organization Pulmonary Hypertension group 2: pulmonary hypertension due to left heart disease in the adult-a summary statement from the Pulmonary Hypertension Council of the International Society for Heart and Lung Transplantation. J Heart Lung Transplant. 2012;31:913-33.

4. Mikus E, Stepanenko A, Krabatsch T, Loforte A, Dandel M, Lehmkuhl HB, et al. Reversibility of fixed pulmonary hypertension in left ventricular assist device support recipients. Eur J Cardiothorac Surg. 2011;40:971-7.

5. Etz CD, Welp HA, Tjan TD, Hoffmeier A, Weigang E, Scheld HH, et al. Medically refractory pulmonary hypertension: treatment with nonpulsatile left ventricular assist devices. Ann Thorac Surg. 2007;83:1697-705.

6. Martin J, Siegenthaler MP, Friesewinkel O, Fader T, van de Loo A, Trummer G, et al. Implantable left ventricular assist device for treatment of pulmonary hypertension in candidates for orthotopic heart transplantation-a preliminary study. Eur J Cardiothorac Surg. 2004;25:971-7.

7. Zimpfer D, Zrunek P, Sandner S, Schima H, Grimm M, Zuckermann A, et al. Post-transplant survival after lowering fixed pulmonary hypertension using left ventricular assist devices. Eur J Cardiothorac Surg. 2007;31:698-702.

8. Zimpfer D, Zrunek P, Roethy W, Czerny M, Schima H, Huber L, et al. Left ventricular assist devices decrease fixed pulmonary hypertension in cardiac transplant candidates. J Thorac Cardiovasc Surg. 2007;133:689-95.
9. Adamson RM, Dembitsky WP, Jaski BE, Daily PO, Moreno R, Kim JC, et al. Left ventricular assist device support of medically unresponsive pulmonary hypertension and aortic insufficiency. ASAIO J. 1997;43:365-9.

10. Aronson D, Eitan A, Dragu R, Burger AJ. Relationship between reactive pulmonary hypertension and mortality in patients with acute decompensated heart failure. Circ Heart Fail. 2011;4:644-50.

11. Pons J, Leblanc MH, Bernier M, Cantin B, Bourgault C, Bergeron S, et al. Effects of chronic sildenafil use on pulmonary hemodynamics and clinical outcomes in heart transplantation. J Heart Lung Transplant. 2012;31:1281-7.

12. Stehlik J, Movsesian MA. Combined use of PDE5 inhibitors and nitrates in the treatment of pulmonary arterial hypertension in patients with heart failure. $J$ Card Fail. 2009;15:31-4.

13. Klotz S, Wenzelburger F, Stypmann J, Welp H, Drees G, Schmid C, et al. Reversible pulmonary hypertension in heart transplant candidates: to transplant or not to transplant. Ann Thorac Surg. 2006;82:1770-3.

14. Murali S, Uretsky BF, Reddy PS, Tokarczyk TR, Betschart AR. Reversibility of pulmonary hypertension in congestive heart failure patients evaluated for cardiac transplantation: comparative effects of various pharmacologic agents. Am Heart J. 1991;122:1375-81.

15. Butler J, Stankewicz MA, Wu J, Chomsky DB, Howser RL, Khadim G, et al. Pretransplant reversible pulmonary hypertension predicts higher risk for mortality after cardiac transplantation. J Heart Lung Transplant. 2005;24:170-7.

16. Mehra MR, Kobashigawa J, Starling R, Russell S, Uber PA, Parameshwar J, et al. Listing criteria for heart transplantation: International Society for Heart and Lung Transplantation guidelines for the care of cardiac transplant candidates-2006. J Heart Lung Transplant. 2006;25:1024-42.

17. Starling RC, Naka Y, Boyle AJ, Gonzalez-Stawinski G, John R, Jorde U, et al. Results of the post-U.S. Food and Drug Administration-approval study with a continuous flow left ventricular assist device as a bridge to heart transplantation: a prospective study using the INTERMACS (Interagency Registry for Mechanically Assisted Circulatory Support). J Am Coll Cardiol. 2011;57:1890-8.

18. Pagani FD, Miller LW, Russell SD, Aaronson KD, John R, Boyle AJ, et al. Extended mechanical circulatory support with a continuous-flow rotary left ventricular assist device. J Am Coll Cardiol. 2009;54:312-21.

19. Alba AC, Rao V, Ross HJ, Jensen AS, Sander K, Gustafsson F, et al. Impact of fixed pulmonary hypertension on post-heart transplant outcomes in bridge-totransplant patients. J Heart Lung Transplant. 2010;29:1253-8.

20. Torre-Amione G, Southard RE, Loebe MM, Youker KA, Bruckner B, Noon GP, et al. Reversal of secondary pulmonary hypertension by axial and pulsatile mechanical circulatory support. J Heart Lung Transplant. 2010;29:195-200.

21. Pagnamenta A, Dewachter C, McEntee K, Fesler P, Brimioulle S, Naeije R. Early right ventriculo-arterial uncoupling in borderline pulmonary hypertension on experimental heart failure. J Appl Physiol (1985). 2010;109:1080-5.

Key Words: pulmonary hypertension, ventricular assist device, heart transplantation

\section{Discussion}

Dr A. Babu (Aurora, Colo). Dr Tsukashita, excellent presentation. Your series adds to the literature on PVR reduction affected by a LVAD. A couple of questions.

What is unique about your series is the correlation of these groups of patients to their post-heart transplant outcome, and clearly you showed a relatively high acute mortality rate after transplant in the patients who previously had a high PVR, and the question is, why do these patients have a higher mortality? You talk about them having a higher incidence of primary graft dysfunction. Was this right ventricular failure, and if so, is there anything we can do in this group of patients to have a lower threshold to place early mechanical support?

Dr Tsukashita. Of 29 patients whose PVR was high, 6 patients died postoperatively, I mean, after heart 
transplantation, and of 6 patients who died, 4 patients had primary graft failure. So the primary cause of death in the high PVR group was primary graft failure. All those 4 patients required a biventricular assist device intraoperatively, and echocardiography showed biventricular dysfunction, not only right ventricular dysfunction.

Dr M. Acker (Philadelphia, Pa). But you didn't modify your donor selection in that group, because you assumed and showed that the PVR went down. Do you think going on that if you actually selected a bigger heart, one more robust, that that would modify your primary graft dysfunction? This is a very important question.

Dr Tsukashita. We didn't see a difference.

Dr Acker. I know. What I am suggesting, looking at these results going forward, maybe that would make the difference and decrease your primary graft dysfunction. Yoshi?

Dr Y. Naka (New York, NY). We attempted to choose the larger donor or the male donor, but often we were not able to achieve it, and the recipient is having device-related complications and they tend to stay, like the device. So the complication rate is maybe a bit higher, too.

Dr Acker. We didn't want to usurp our primary discussant's podium, so go ahead, second question.

Dr Babu. We do know that the HeartWare ventricular assist device probably affects less decompression of the ventricle and perhaps less decompression of mitral regurgitation, and that may have an effect on PVR decrease over time. I know your percentage of HeartWare ventricular assist device is small, but I wanted to know if you had any observations in regard to that.
I noticed a group of your patients received mitral valve repair at the time of LVAD implant, and perhaps that may have an effect on PVR reduction over time as well. Can you comment on those 2 groups?

Dr Tsukashita. We have seen more reduction in PVR after LVAD implantation in the patients, particularly in those who received a mitral valve repair concomitantly than in those who did not. But we didn't specifically look at the post-heart transplant data on the patients who received a HeartWare device.

Dr M. Ruel (Ottawa, Ontario, Canada). Do we really know when these patients are ready for transplant? We occasionally all get burned with this situation. We do a right heart catheterization at 6 months on the ventricular assist device, the PVR goes from 8 to 3, and we're all happy, we clap our hands, and still we occasionally get in trouble at the time of transplant.

You have 20\% mortality in this population; this is high in a transplant series. Again, do we really have the right technology and approach to test these patients?

There are 2 components to PVR: the venous component and the arterial component. The venous component quickly disappears with any LVAD that works well. But occasionally there's still an important arterial component, and we get burned by it. Again, do we have the right evaluation?

Dr Tsukashita. For those patients who died with primary graft failure after heart transplantation in the high PVR group, we have the post-LVAD right heart catheterization data, which show that the PVR was less than 3. So we really don't know the cause of primary graft failure after heart transplant.

Readers who found these articles interesting may also like to read the following papers found in recent and future issues of our sister publications, Seminars in Thoracic and Cardiovascular Surgery and Operative Techniques in Thoracic and Cardiovascular Surgery!

\section{Cardiothoracic Transplantation and Mechanical Circulatory Support}

State of the Art: The State of the Art in Corporeal Membrane Oxygenation. Steve K. Singh. Semin Thorac Cardiovasc Surg 2015; Spring; 27(1):17-23.

Techniques for lung procurement following donation after circulatory death. Pankaj Saxena. Oper Tech Thorac Cardiovasc Surg 2014; Autumn; 19(3):380-393.

Techniques for venoarterial ECMO support and conversion to temporary left ventricular Assist Device. Ashok Babu. Oper Tech Thorac Cardiovasc Surg 2014; Autumn; 19(3):253-394.

Non-sternotomy approaches to left ventricular assist device placement. Simon Maltais. Oper Tech Thorac Cardiovasc Surg 2014; Autumn; 19(3):276-291.

Non-Sternotomy Approaches to Left Ventricular Assist Device Placement: Combined Left Subcostal - Right Mini-Thoracotomy Technique. Anelechi Anyanwu. Oper Tech Thorac Cardiovasc Surg 2014; Autumn; 19(3):254-275.

Ex Vivo Lung Perfusion. Marcelo Cypel. Oper Tech Thorac Cardiovasc Surg 2014; Winter, 19(4):433-442.

Subcostal Approach to Replacement of a HeartMate II Device: Indications and Technique. Nader Moazami. Oper Tech Thorac Cardiovasc Surg 2014; Winter, 19(4):443-453. 

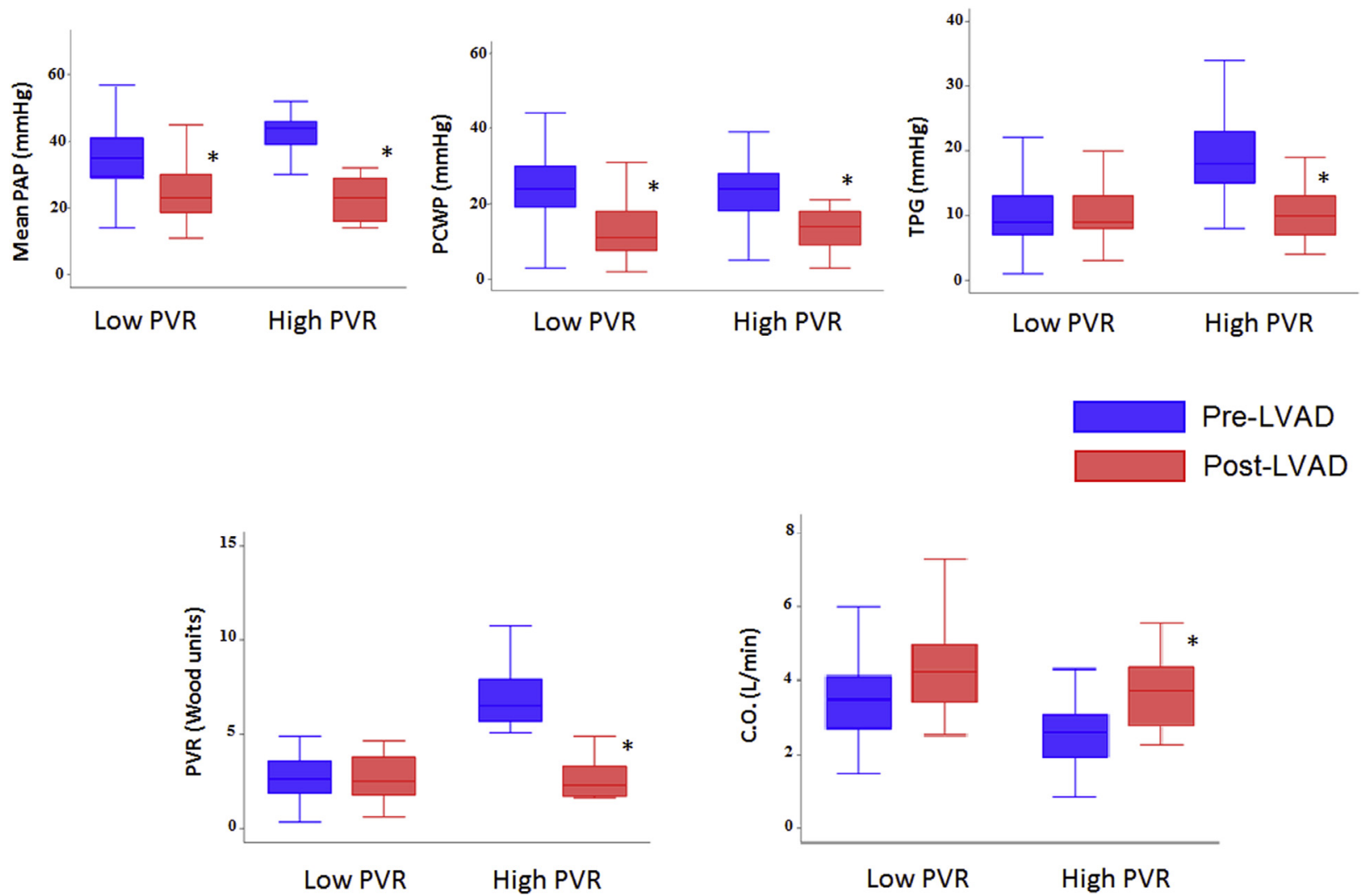

FIGURE E1. Hemodynamic variables pre- and post-LVAD implantation. $* P<.05$ pre-LVAD versus post-LVAD parameters. $C O$, Cardiac output; $L V A D$, left ventricular assist device; $P A P$, pulmonary artery pressure; $P C W P$, pulmonary capillary wedge pressure; $P V R$, pulmonary vascular resistance; $T P G$, transpulmonary pressure gradient. 
TABLE E1. All causes of post-orthotopic heart transplantation mortality during follow-up

\begin{tabular}{lccr}
\hline \multicolumn{1}{c}{ Cause of death } & Low PVR & High PVR & Total \\
\hline Primary graft failure & $1(1,0)$ & $4(4,0)$ & 5 \\
Late graft failure & $2(1,1)$ & & 2 \\
Rejection & $1(0,1)$ & & 1 \\
Sepsis & $6(4,2)$ & $1(1,0)$ & 7 \\
Pneumonia & $1(0,1)$ & & 1 \\
Cardiac tamponade & $1(1,0)$ & & 1 \\
Stroke & & $1(1,0)$ & 1 \\
Cancer & $1(0,1)$ & & 1 \\
Gastroenteritis & $1(0,1)$ & & 1 \\
Clostridium difficile colitis & $1(0,1)$ & & 1 \\
Unknown & $5(1,4)$ & & 5 \\
total & $20(7,13)$ & $6(6,0)$ & 26 \\
\hline
\end{tabular}

Data are presented as $n$. The numbers in parentheses represent the early and late mortality, respectively. $P V R$, Pulmonary vascular resistance. 